\title{
X-Ray Long Period of Poly(acrylonitrile) Fibers Prepared by Solid-State Coextrusion of Nascent Powder
}

\author{
Daisuke SAWAI and Tetsuo KANAMOTO ${ }^{\dagger}$ \\ Department of Applied Chemistry, Science University of Tokyo, Kagurazaka, \\ Shinjuku-ku, Tokyo 162-8601, Japan
}

(Received May 23, 2000; Accepted June 19, 2000)

\begin{abstract}
This paper examines small-angle X-Ray scattering (SAXS) of poly(acrylonitrile) (PAN) fibers prepared by solid-state coextrusion of a film of nascent PAN formed under controlled conditions, as reported by Kumamaru et al. [J. Cryst. Growth, 48, 202 (1980)]. Although solution-cast PAN films or fibers and their drawn products generally show no X-Ray long-period scattering, the nascent PAN and the fibers prepared from it by solid-state coextrusion exhibited a clear SAXS maximum, depending on the extrusion temperature $\left(T_{\text {ext }}\right)$ and draw ratio (EDR). For extrusions below $110^{\circ} \mathrm{C}$ or above $140^{\circ} \mathrm{C}$, the SAXS was too broad to determine the scattering maximum. Upon extrusion at a $T_{\text {ext }}$ of $110^{-}-140^{\circ} \mathrm{C}$ and an EDR of $6-20$, the long-period scattering was clearly observed on the meridian. At a given $T_{\text {ext }}$, the long period stayed at a constant value, independently of the sample EDR in the EDR range of 6-20. However, at a higher EDR $>20$, no long period was distinguishable. It increased linearly with $T_{\text {ext }}$ from the initial 7.7 to $11.5 \mathrm{~nm}$ for the extrusion at $T_{\text {ext }}$ $=140^{\circ} \mathrm{C}$, which was $177^{\circ} \mathrm{C}$ lower than the estimated melting temperature of $\mathrm{PAN}\left(T_{\mathrm{m}}=317^{\circ} \mathrm{C}\right)$. A possible mechanism of the long-period increase upon extrusion far below the $T_{\mathrm{m}}$ was discussed based on the enhanced chain mobility in the crystalline phase above the crystal/crystal reversible transition combined with the heat evolved during local necking upon extrusion drawing. These observations reveal that the absence or presence of an X-Ray long-period scattering for PAN fibers depends on the initial morphology and the drawing variables.

KEYWORDS Poly(acrylonitrile) Fibers / X-Ray Long Period / Nascent Powder / Coextrusion Drawing / Effect of Extrusion Variables /
\end{abstract}

Poly(acrylonitrile) (PAN) is an unusual polymer in that even an atactic PAN can crystallize. This polymer has high cohesive energy density and fairly high chain stiffness ${ }^{1}$ due to the bulky nitrile groups with a large dipole. Thus, PAN has a high estimated melting temperature $\left(T_{\mathrm{m}}\right)$ of $317^{\circ} \mathrm{C}^{1}$ and undergoes degradation below the $T_{\mathrm{m}}$. Solution-cast fibers and films of PAN and their drawn products generally show no small-angle X-Ray scattering (SAXS) maximum, ${ }^{2-4}$ and it is therefore usually assumed that the PAN fibers have a single-phase paracrystalline structure. ${ }^{5}$ In contrast, Hinrichsen ${ }^{6,7}$ observed a clear X-Ray long-period scattering for a series of as-drawn and annealed PAN fibers and proposed a two-phase structure consisting of less-ordered and threedimensionally ordered phases based on the SAXS and wide-angle X-Ray diffraction (WAXD). Furthermore, some authors ${ }^{6-9}$ observed a clear SAXS maximum for PAN fibers annealed at high temperatures $\left(220-300^{\circ} \mathrm{C}\right)$, which might be associated with the cyclization of nitrile groups that took place during the annealing. ${ }^{9}$ However, the actual reason for the appearance or absence of the $\mathrm{X}$ Ray long-period scattering in PAN fibers has not yet been clarified.

Kumamaru et al. ${ }^{10}$ found that nascent PAN, obtained by thermal polymerization of acrylonitrile in solution under the specific conditions, consisted of well-defined hexagonal single-crystals with a more regular morphology than those precipitated from a dilute solution. ${ }^{11}$ The film, obtained by filtering the crystal suspension, showed a clear SAXS maximum that gave a definite long period corresponding to the lamellar thickness. We ${ }^{12}$ have shown that although such a film of nascent PAN was too brittle to be drawn by straight tensile drawing, it could be successfully ultradrawn by solid-state coextrusion developed by Porter et al. ${ }^{13}$ Further, we ${ }^{14}$ have found that lamallar thickening occurred in such nascent PAN crystals upon annealing far below (by $\sim 150^{\circ} \mathrm{C}$ ) the estimated melting temperature of $\operatorname{PAN}\left(317^{\circ} \mathrm{C}\right) .^{1}$

In this work, the effects of extrusion draw ratio (EDR) and temperature $\left(T_{\text {ext }}\right)$ on X-Ray long-period scattering have been studied for fibers prepared by solid-state coextrusion of a nascent PAN film. The results provide a possible explanation for the appearance or absence of an XRay long-period scattering in PAN fibers, depending on the preparation conditions including the initial morphology and the drawing conditions.

\section{EXPERIMENTAL}

Nascent PAN was precipitated during thermal polymerization of acrylonitrile (AN) in a solution according to the procedures reported by Kumamaru et al. ${ }^{10} \mathrm{~A} 60 \%$ solution of $\mathrm{AN}$ in $N, N$-dimethylformamide (DMF) was gradually heated from room temperature to $98^{\circ} \mathrm{C}$ and held there for $1 \mathrm{~h}$. While the solution was kept at this temperature, the mother liquid $(\mathrm{DMF}+\mathrm{AN})$ became cloudy, and hexagonal lamellae and aggregates of such single crystals precipitated. ${ }^{10,12}$ A film of nascent PAN was obtained by slowly filtering the crystal suspension at room temperature. The wet film was dried in air and then in vacuo at $50^{\circ} \mathrm{C}$ for $24 \mathrm{~h}$. The resultant film contained less than $0.3 \mathrm{wt} \%$ of the solvent, as determined by thermogravimetric analysis. The viscosity average molecular weight of this sample was 78000 , as determined

\footnotetext{
${ }^{\dagger}$ To whom correspondence should be addressed (E-mail: tkanamot@ch.kagu.sut.ac.jp).
} 

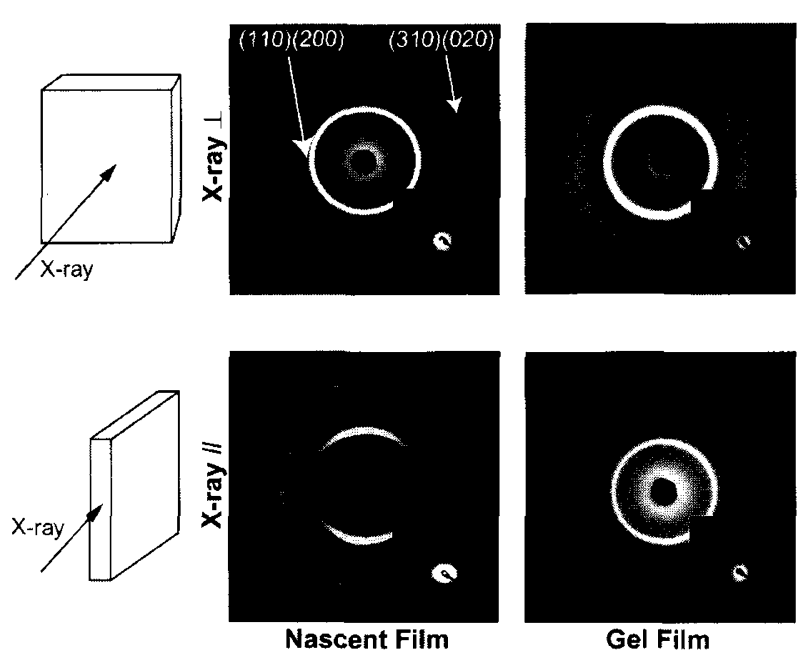

Figure 1. WAXD and SAXS patterns of a nascent PAN film (left) and a gel film (right). The X-Ray beam was directed perpendicularly (top) and parallel (bottom) to the film surface.

from an intrinsic viscosity/molecular weight relation. ${ }^{15}$

A gel film was also prepared to compare the structure with the nascent PAN film. For this, a polymer solution with a concentration of $10 \mathrm{wt} \%$ was prepared by dissolving the requisite amount of the nascent PAN in $N, N^{\prime}$ dimethylformamide at $100^{\circ} \mathrm{C}$. The hot solution was quenched at $0^{\circ} \mathrm{C}$ for $2 \mathrm{~h}$ to make gel. The wet gel film was extracted with methanol and then dried in air, followed by further drying in vacuo at $50^{\circ} \mathrm{C}$ to constant weight.

For solid-state coextrusion, a $5 \mathrm{~mm}$ wide and $70 \mathrm{~mm}$ long strip cut from the nascent powder film was positioned between two longitudinally split-billet halves of high-density polyethylene for extrusion at a temperature $\left(T_{\text {ext }}\right)<130^{\circ} \mathrm{C}$ or poly(4-methyl-1-pentene) at a $T_{\text {ext }}$ $>130^{\circ} \mathrm{C}$, and the assembly was coextruded through a conical die at constant temperatures of $100-160^{\circ} \mathrm{C}$.

Wide-angle X-Ray diffraction (WAXD) patterns were recorded with a flat-plate camera and diffractometer scans. The photographs were obtained with $\mathrm{Cu}-\mathrm{K} \alpha$ radiation monochromatized with a graphite crystal generated at $40 \mathrm{kV}$ and $25 \mathrm{~mA}$ on a Rigaku Geigerflex RAD3A. Crystalline chain orientation was evaluated by the Herman-Stein orientation function, ${ }^{16} f_{c}$, calculated from the azimuthal intensity distribution of the overlapped (110) (200) reflections at around $2 \theta=17^{\circ}$ assuming fiber symmetry. Small-angle X-Ray scattering (SAXS) patterns were recorded with a vacuum camera using $\mathrm{Ni}$ filtered $\mathrm{Cu}-\mathrm{K} \alpha$ radiation generated on a Rigaku Rotaflex RU-200. The distance from the sample to the photographic film was $300 \mathrm{~mm}$.

\section{RESULTS AND DISCUSSION}

Figure 1 shows WAXD and SAXS patterns for a nascent PAN powder film and a gel film prepared by quenching a $10 \mathrm{wt} \%$ solution of the nascent PAN in DMF. When the incident X-Ray beam was directed parallel to the wide surface of the nascent film, a SAXS maximum appeared on the equator and the wide-angle overlapped (110) (200) and (310) (020) reflections on the meridian. However, when the beam was directed per- pendicularly to the film surface, no SAXS long period was observed and the wide-angle reflections consisted of smooth rings, as usually observed for single-crystal mats of other polymers. ${ }^{17}$ In contrast, the gel film showed no SAXS long period and the wide-angle reflections appeared as smooth rings, independently of the direction of the incident beam. These observations revealed that the nascent PAN film consisted of chain-folded lamellae of $7.7 \mathrm{~nm}$ thickness with a less-ordered/crystalline twophase structure. Furthermore, the molecular chains were oriented perpendicularly to the lamellae stacked parallel to the wide surface of the film. In contrast, the absence of an X-Ray long-period scattering for the solution-cast gel film did not suggest the existence of any lamellar structure within the film. Furthermore, the fibers prepared by solid-state coextrusion of the gel film also showed no long-period scattering independently of the extrusion conditions. It was confirmed by the WAXD patterns that these PAN samples adopted an orthorhombic chain packing in the crystalline phase, as discussed in previous papers. ${ }^{18,19}$

\section{Effect of Extrusion Draw Ratio}

Figure 2 shows the SAXS and WAXD patterns for a draw ratio series prepared by solid-state coextrusion of a nascent PAN film at $T_{\text {ext }}=140^{\circ} \mathrm{C}$ and recorded with the incident beam parallel to the wide surfaces of the fibers. Although an extrudate with a low EDR of 3 showed slightly different patterns depending on the direction of the incident beam, those of the higher EDR's $\geq 6$ showed identical patterns independently of the direction of the incident beam. Upon extrusion at an EDR of 3, a new SAXS maximum appeared on the meridian in addition to the equatorial scattering from the initial lamellae. Concurrent with this change in the SAXS, the WAXD intensity maxima for the overlapped (110) (200) and (310) (020) reflections fell on the equator. These SAXS and WAXD patterns indicate that part of the initial lamellae, which were aligned parallel to the extrusion direction, rotated by $\sim 90^{\circ}$ and correspondingly the molecular chains were selectively oriented along this direction. The SAXS patterns of the extrudates with EDR's $\geq 6$ exhibited a scattering maximum only on the meridian showing their typical fiber structure. However, highly drawn fibers with EDR's $>20$ showed strong void scattering extending along the equator but the meridional scattering was too weak to determine the intensity maximum. The series of WAXD patterns showed that the chain orientation increased steadily with EDR, as demonstrated by the crystalline chain orientation function $f_{c}=0.850$ at an $\mathrm{EDR}=9$ and $f_{c}=0.950$ at an $\mathrm{EDR}=30$.

Figure 3 shows the long period as a function of EDR for the extrusion drawing of a nascent PAN film at $T_{\text {ext }}$ 's of 120 and $140^{\circ} \mathrm{C}$. At a low EDR of 3, the long period of a new fibrillar structure, which appeared on the meridian, was $8.4 \mathrm{~nm}$ for the extrusion at $T_{\text {ext }}=120^{\circ} \mathrm{C}$ and $9.8 \mathrm{~nm}$ at $T_{\text {ext }}=140^{\circ} \mathrm{C}$. These values were slightly larger than the initial long period of $7.7 \mathrm{~nm}$ for the nascent PAN. Upon extrusion to a slightly higher EDR of 6 , the meridional long period further increased to $9.6 \mathrm{~nm}$ at $T_{\text {ext }}$ $=120^{\circ} \mathrm{C}$ and $11.5 \mathrm{~nm}$ at $T_{\text {ext }}=140^{\circ} \mathrm{C}$ and stayed constant at yet higher EDR's. 


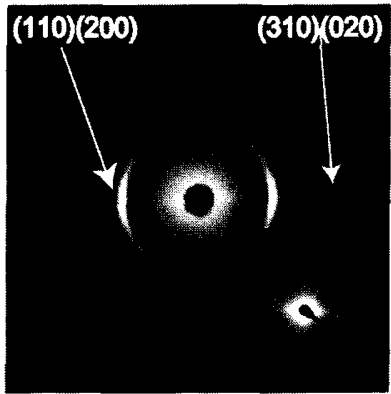

$E D R=3$

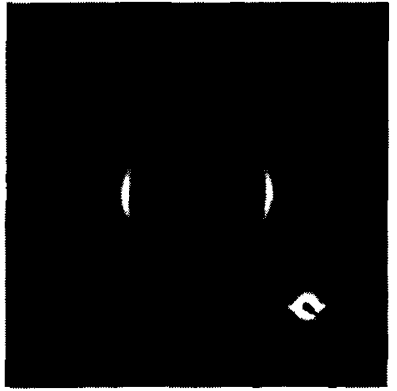

EDR $=9\left(f_{C}=0.850\right)$

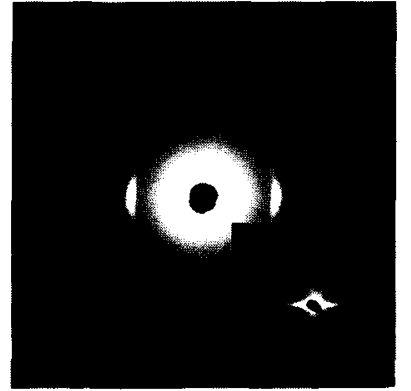

$\mathbf{E D R}=16\left(f_{\mathrm{c}}=0.911\right)$

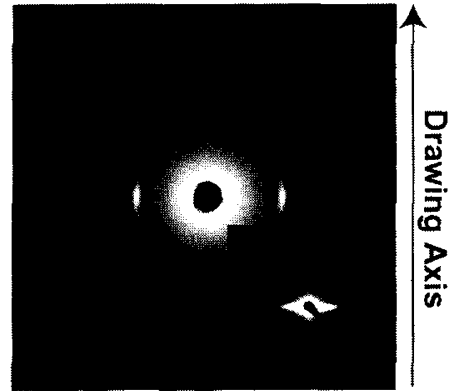

$\mathrm{EDR}=\mathbf{3 0}\left(f_{\mathrm{c}}=0.950\right)$

Figure 2. WAXD and SAXS patterns for a draw ratio series of PAN fibers prepared by solid-state coextrusion of a nascent PAN film at a $T_{\text {ext }}$ of $140^{\circ} \mathrm{C}$. The incident beam was directed parallel to the wide surfaces of the extrudates. Note that the extrudate with a low EDR of 3 shows a new SAXS maximum on the meridian in addition to a fairly strong scattering maximum on the equator due to the initial lamellae. The fibers with EDR's $\geq 6$ show a long-period scattering only on the meridian.

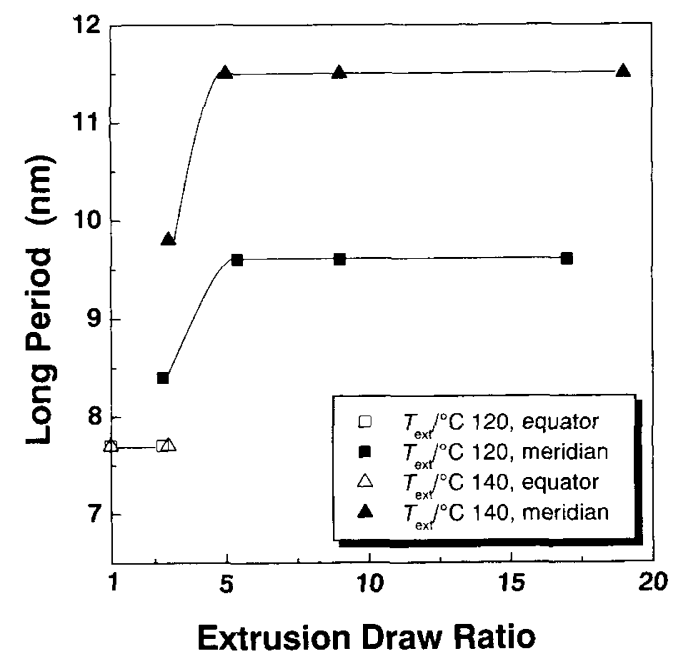

Figure 3. Long period as a function of the extrusion draw ratio for the extrusion at $T_{\text {ext }}$ 's of 120 and $140^{\circ} \mathrm{C}$.

\section{Effect of Extrusion Temperature}

Figure 4 shows the WAXD and SAXS patterns for a series of samples prepared at different $T_{\text {ext }}$ 's. They had a constant EDR of 9 , at which the transformation of the initial lamellae into a new fibrillar structure had been completed and the long period reached a constant value characteristic for each of the $T_{\text {ext }}$ 's. The samples prepared at lower $T_{\text {ext }}{ }^{\prime} \mathrm{s} \leq 100^{\circ} \mathrm{C}$ or at higher $T_{\text {ext }}{ }^{\prime} \mathrm{s} \geq 150^{\circ} \mathrm{C}$ showed no clear SAXS maxima, although their WAXD patterns showed no significant differences. Even though the reason is not clear, this result might be due to a significant variation in the lamellar thickness upon extrusion at these lower or higher $T_{\text {ext }}$ 's. Thus, the observation of a long-period scattering maximum was limited to the extrudates with an EDR $<20$ which were prepared at $T_{\text {ext }}$ 's between $110-140^{\circ} \mathrm{C}$. The long periods increased linearly with $T_{\text {ext }}$ as shown in Figure 5 . The increase of the long period for a nascent PAN film upon annealing ${ }^{14}$ was also shown for comparison.

Two mechanisms have been proposed for lamellar thickening in crystalline polymers. ${ }^{20-23}$ One is associated with the motion of entire segments of the mole- cules $^{20}$ or the motion of a point dislocation ${ }^{21}$ along the chain within a crystal. The other one ${ }^{22,23}$ explains lamellar thickening by the partial melting of the initial lamellae followed by recrystallization into thicker lamellae at a higher temperature. Since the lamellar thickening was observed here upon extrusion of the nascent PAN even at $T_{\text {ext }}$ 's of $110-140^{\circ} \mathrm{C}$, far below the estimated $T_{\mathrm{m}}$ of PAN $\left(317^{\circ} \mathrm{C}\right),{ }^{1}$ the former mechanism was likely more important. Indeed, it was found in our previous papers $^{18,24}$ that highly drawn PAN fibers exhibit a clear crystal/crystal transition from orthorhombic to hexagonal chain packing at $140-160^{\circ} \mathrm{C}$, depending on the sample draw ratio. This transition is thermally reversible and above which the molecular motion in the crystalline phase is highly activated. Furthermore, the fibers with low draw ratios showed that the transition occurred in a wider range of temperature. ${ }^{24}$

The nascent PAN showed a broad DSC endothermic peak at $160^{\circ} \mathrm{C}$ due to the reversible crystal/crystal transition. ${ }^{14}$ The long period of this sample increased upon annealing above the transition temperature, which was $\sim 157^{\circ} \mathrm{C}$ lower than the $T_{\mathrm{m}}$ of PAN $\left(317^{\circ} \mathrm{C}\right)$ as seen in Figure 5. Therefore, the lamellar thickening was ascribed to the molecular motion activated above the crystal/crystal transition. ${ }^{14,25}$ It is noted that the long period of an extrusion-drawn PAN fiber increased slightly upon extrusion even at $110^{\circ} \mathrm{C},-50^{\circ} \mathrm{C}$ lower than the crystal transition temperature of the nascent PAN (Figure 5) and even $\sim 207^{\circ} \mathrm{C}$ lower than the $T_{\mathrm{m}}$. Although the deformation during solid-state extrusion proceeded uniformly at the macroscopic level, ${ }^{26}$ it was initiated by the local necking of the lamellae followed by their successive unlabeling at the microscopic level, which might evolve heat. The actual temperature at the neck region was not known. Nevertheless, the increased chain mobility caused by the temperature increase was likely one of the most important causes for the long-period increase upon extrusion drawing of the nascent PAN observed here. Such an explanation is consistent with the experimental fact that the new long period on the meridian increased with increasing the $T_{\text {ext }}$ (Figure 5).

Further, a sample with a low EDR of 3 showed two long-period scattering maxima on the equator and the meridian (Figure 2), indicating that only part of the initial lamellae transformed into a new fibrillar structure. 


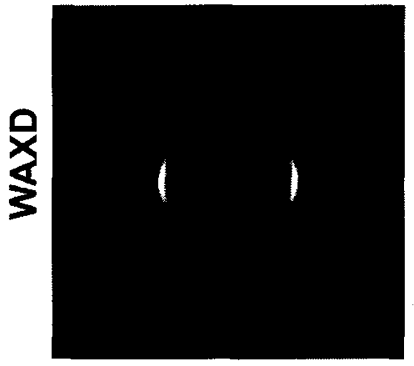

$T_{\text {ext }}=100^{\circ} \mathrm{C}$

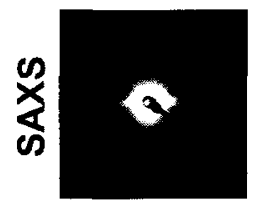

$T$ ext $=100^{\circ} \mathrm{C}$

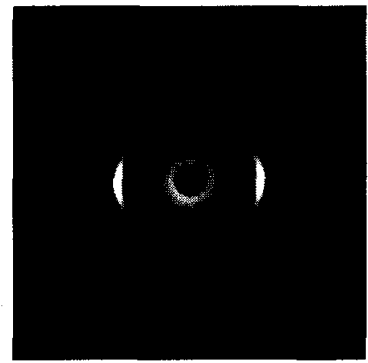

$T_{\text {ext }}=120^{\circ} \mathrm{C}$

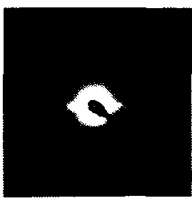

$T_{\text {ext }}=120^{\circ} \mathrm{C}$

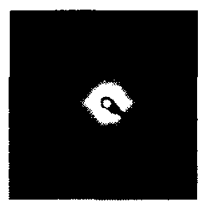

$T_{\text {ext }}=140^{\circ} \mathrm{C}$

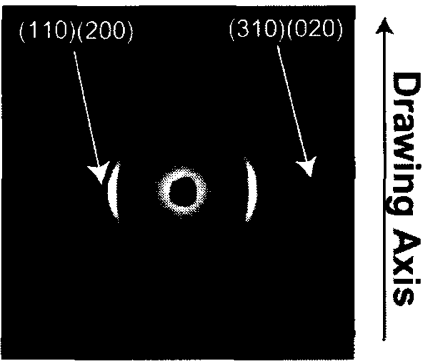

$T_{\text {ext }}=180^{\circ} \mathrm{C}$

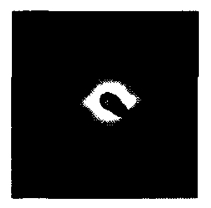

$T_{\text {ext }}=150^{\circ} \mathrm{C}$

Figure 4. WAXD and SAXS patterns for a series of PAN fibers prepared at different $T_{\text {ext }}$ 's and a constant EDR of 9 .

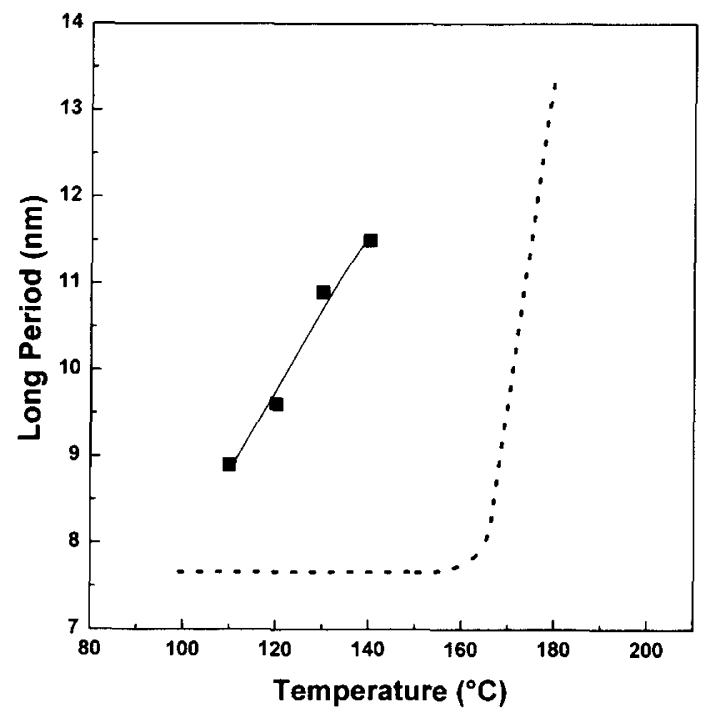

Figure 5. Long periods calculated from the meridional SAXS maxima of the PAN fibers as a function of $T_{\text {ext }}$. The change of long period upon annealing of the nascent PAN film at $100-180^{\circ} \mathrm{C}$ is also shown by a dotted line ${ }^{14}$ for comparison.

This suggests that the heat evolved during such a microneck deformation was smaller than that evolved during extrusion at a higher EDR, at which all of the initial lamellae were transformed into a fibrous structure. Therefore, the actual temperature of the deforming portion might have been lower for the former sample than for the latter sample. Thus, the meridional long period of the former was smaller than those of the highly drawn samples prepared at the same $T_{\text {ext }}$ as shown in Figure 3. This observation is also consistent with the above mechanism that the long-period increase was promoted by the temperature rise at the necking region even when the $T_{\text {ext }}$ was significantly lower than the crystal/crystal transition.

\section{CONCLUSION}

PAN fibers ${ }^{2-4}$ generally show no small-angle X-Ray scattering maximum corresponding to the long period except for a few cases. ${ }^{6,7}$ However, the fibers prepared by solid-state coextrusion of a nascent PAN film exhibited clear X-Ray long-period scattering depending on the extrusion conditions. Thus, the effects of EDR and $T_{\text {ext }}$ have been studied. The extrusion-drawn fibers prepared from a nascent PAN film at a $T_{\text {ext }}$ of $110-140^{\circ} \mathrm{C}$ exhibited an X-Ray long-period scattering. However, those prepared at lower $T_{\text {ext }}$ ' $\leq 100^{\circ} \mathrm{C}$ or at higher $T_{\text {ext }} \geq 150^{\circ} \mathrm{C}$ showed a SAXS which was too broad to determine the scattering maximum. Furthermore, the highly drawn samples with EDR's $>20$ also showed no clear longperiod scattering, independently of the $T_{\text {ext }}$. Thus, the XRay long period was observable for the PAN fibers prepared at $T_{\text {ext }}$ 's of $110-140^{\circ} \mathrm{C}$ and EDR's $<20$. At a low EDR of 3 , the extrusion-drawn sample showed longperiod scattering maxima both on the equator and the meridian, revealing that portion of the initial lamellae transformed into a fibrous structure. At higher EDR's $\geq 6$, all the initial lamellae were transformed into a new fibrous structure as indicated by the appearance of a long-period scattering only on the meridian. The long period increased linearly with increasing $T_{\text {ext }}$, as generally observed upon drawing of other polymers. ${ }^{25}$ The results observed in this work provide a possible explanation for the presence or absence of the X-Ray longperiod scattering depending on preparation conditions, including the morphology of the starting PAN and the drawing conditions.

Acknowledgment. This work was partly supported by a Grant-in-Aid from the Ministry of Education, Science and Culture of Japan (\#11650934). T. K. expresses his appreciation to the Center for New Materials Research of the Science University of Tokyo for financial support received. D. S. expresses his appreciation to the JSPS Research Fellowship for Young Scientists. 


\section{REFERENCES}

1. W. R. Krigbaum and N. Tokita, J. Polym. Sci., 43, 647 (1960).

2. C. R. Bohn, J. R. Schaefgen, and W. O. Statton, J. Polym. Sci., 55, 531 (1961).

3. M. Takahashi and Y. Nukushina, J. Polym. Sci., 56, 19 (1962)

4. A. K. Gupta and N. Chand, Eur. Polym. J., 15, 899 (1979).

5. P. H. Lindenmeyer and R. Hoseman, J. Appl. Phys. 24, 42 (1963).

6. G. Hinrichsen, J. Polym. Sci. Part C, 38, 303 (1972).

7. G. Hinrichsen, J. Appl. Polym. Sci., 17, 3305 (1973).

8. N. Chatterjee, S. Basu, S. K. Palit, and M. M. Maiti, J. Polym. Polym. Sci. Phys. Ed., 33, 1705 (1995).

9. A. F. Thünemann and W. Ruland, Macromolecules, 33, 2626 (2000).

10. F. Kumamaru, T. Kajiyama, and M. Takayanagi, J. Cryst. Growth, 48, 202 (1980).

11. J. J. Klement and P. H. Geil, J. Polym. Sci., A-2, 6, 1381 (1968).

12. T. Kameda, A. Yamane, T. Kanamoto, M. Ito, and R. S. Porter, Polym. Sci. (USSR), A 38, 737 (1996).

13. P. D. Griswold, A. E. Zachariades, and R. S. Porter, Polym. Eng. Sci., 18, 11 (1978)
14. D. Sawai, M. Miyamoto, T. Kanamoto, and M. Ito, J. Polym Sci., Polym. Phys. Ed., 38, 2571 (2000).

15. J. Brandrup, E. H. Immergut, and E. A. Grulke, "Polymer Handbook", 4th ed, John Wiley \& Sons, New York, Chichester, Weinheim, Brisbane, Singapore, Toronto, 1999.

16. M. Kakudo and N. Kasai, "X-Ray Diffraction of Polymers", Maruzen Publisher, Tokyo, 1969.

17. P. H. Geil, "Polymer Single Crystals", Interscience Publishers, New York, London, Sydney, 1962.

18. A. Yamane, D. Sawai, T. Kameda, T. Kanamoto, M. Ito, and R. S. Porter, Macromolecules, 30, 4170 (1997).

19. D. Sawai, A. Yamane, H. Takahashi, T. Kanamoto, M. Ito, and R. S. Porter, J. Polym. Sci. Polym. Phys. Ed., 36, 629 (1998).

20. A. Peterlin, Polymer, 6, 25 (1965).

21. H. D. Reneker, J. Polym. Sci., 59, 539 (1962).

22. E. W. Fisher and G. F. Schmidt, Angew. Chem., 74, 551 (1962).

23. M. Todoki and T. Kawaguchi, J. Polym. Sci., Polym. Phys. Ed., 15, 1067 (1977).

24. D. Sawai, T. Kanamoto, and R. S. Porter, Macromolecules, 31, 2010 (1998).

25. J. Rault, J. M. S., Rev. Macromol. Chem. Phys., C37(2), 335 (1997).

26. T. Kanamoto, A. E. Zachariades, and R. S. Porter, Polym. J., 11, 307 (1979). 